\title{
Association of DNMT1 and DNMT3B polymorphisms with breast cancer risk in Han Chinese women from South China
}

\author{
M.-Y. Sun ${ }^{1 *}$, X.-X. Yang ${ }^{1 *}$, W.-W. Xu' ${ }^{1}$, G.-Y. Yao ${ }^{2}$, H.-Z. Pan ${ }^{3}$ and M. Li ${ }^{1,4}$ \\ ${ }^{1}$ School of Biotechnology, Southern Medical University, Guangzhou, China \\ ${ }^{2}$ Nanfang Hospital, Southern Medical University, Guangzhou, China \\ ${ }^{3}$ Clinical Lab of Affiliated Hospital, Medical College Qingdao University, \\ Qingdao, China \\ ${ }^{4}$ Da An Gene Co., Ltd. of Sun Yat-Sen University, Guangzhou, China \\ *These authors contributed equally to this study. \\ Corresponding author: M. Li \\ E-mail: mingli2006_2006@126.com
}

Genet. Mol. Res. 11 (4): 4330-4341 (2012)

Received December 14, 2011

Accepted June 5, 2012

Published September 26, 2012

DOI http://dx.doi.org/10.4238/2012.September.26.1

\begin{abstract}
Patterns of DNA methylation are established and maintained by a family of DNA methyltransferases (DNMTs). Aberrant promoter DNA methylation of tumor suppressor genes is found in breast cancer. Association studies between DNMT gene polymorphisms and breast cancer in various populations have reported inconsistent results. This study assessed the associations of single nucleotide polymorphisms (SNPs) in DNMT1, DNMT3A, DNMT3B, DNMT3L, and DNMT2 with breast cancer among Han Chinese women from South China. Sixteen SNPs (rs2114724, rs2228611, rs2228612, rs8101866, and rs16999593 in DNMT1; rs13420827, rs11887120, rs13428812, rs1550117, rs11695471, and rs6733301 in DNMT3A; rs2424908, rs2424913, and rs6087990 in DNMT3B; rs113593938 in DNMT3L, and rs11254413 in DNMT2) in 408 women with breast cancer and 469 controls were genotyped using a MassARRAY matrix-assisted laser desorption/ ionization time-of-flight mass spectrometry platform. Two SNPs,
\end{abstract}


rs16999593 in DNMT1 and rs2424908 in DNMT3B, were significantly associated with breast cancer risk. The heterozygous genotype CT of rs16999593 was associated with increased breast cancer risk [odds ratio $(\mathrm{OR})=1.60 ; 95 \%$ confidence interval $(95 \% \mathrm{CI})=1.20-2.14 ; \mathrm{P}=$ $0.0052]$, whereas rs 2424908 was associated with decreased risk $(\mathrm{OR}=$ $0.62 ; 95 \% \mathrm{CI}=0.46-0.84 ; \mathrm{P}=0.0061)$. Other $D N M T$ polymorphisms showed no significant associations with breast cancer risk in the study population. Haplotype CGTC of rs2114724, rs2228611, rs8101866, and rs16999593 in DNMT1 differed significantly as a risk factor between the case and control groups $(\mathrm{OR}=1.51 ; 95 \% \mathrm{CI}=1.18-1.93 ; \mathrm{P}=0.0012)$. The heterozygous genotypes of rs16999593 in DNMT1 and rs2424908 in $D N M T 3 B$ were strongly associated with breast cancer risk.

Key words: DNMT; Breast cancer; Single nucleotide polymorphism; Susceptibility

\section{INTRODUCTION}

DNA methylation, the major epigenetic modification of DNA in mammalian genomes, plays a significant role in normal biological processes such as $\mathrm{X}$ chromosome inactivation, genetic imprinting, genomic stabilization, and gene expression. Aberrant DNA methylation patterns involving hypermethylation or hypomethylation have been associated with the development and progression of various cancers (Jones and Baylin, 2002; Herman and Baylin, 2003; McCabe and Caudill, 2005). Hypermethylation typically occurs at $\mathrm{CpG}$ islands in promoter regions and represses the transcription of tumor suppressor genes. Hypomethylation of genomic cytosine occurs during tumorigenesis (Ehrlich, 2002). DNA methylation is an important regulator of gene transcription, and genes with high levels of 5 -methylcytosine in their promoter regions are transcriptionally silent (Herman and Baylin, 2003).

In mammalian cells, DNA methylation is established and maintained by the DNA methyltransferase family of proteins, called (cytosine-5) DNMTs. These include DNMT1, DNMT3A, DNMT3B, DNMT3L, and DNMT2 (Bestor, 2000). DNMT1, a maintenance methyltransferase, copies DNA methylation patterns to daughter strands during DNA replication. DNMT3A and DNMT3B are closely related and are classified as de novo methyltransferases; they set up DNA methylation patterns early in development. DNMT3L is similar to DNMT3A and DNMT3B and can increase the binding of DNMT3A/DNMT3B to DNA, thereby enhancing de novo methyltransferase activity; however, DNMT3L itself has no catalytic activity. DNMT2 [also known as transfer RNA (tRNA) aspartic acid methyltransferase 1] has enigmatic biological functions. Its DNA methyltransferase activity is comparatively weak, but Goll et al. (2006) have shown that it has a novel tRNA methyltransferase activity on cytosine 38 of the anticodon loop of aspartic acid tRNA. The DNMTs are believed to establish and maintain DNA methylation patterns, and their overexpression in tumors may partly explain aberrant methylation phenomena in cancerous tissues or cells.

Breast cancer is the most frequently diagnosed cancer and the leading cause of 
cancer deaths among women in developing countries (Jemal et al., 2011). Like other cancers, it is initiated by interactions between the environment and genetic defects. Genomewide association studies have shown that many susceptibility polymorphisms of genes are associated with breast cancer. Variants of DNMTs have been evaluated to determine relationships between $D N M T$ polymorphisms and breast cancer risk (Montgomery et al., 2004; Cebrian et al., 2006; Ye et al., 2010; Xiang et al., 2010), but the results have been inconsistent. This study was performed to assess the association between single nucleotide polymorphisms (SNPs) in DNMTs and the risk for breast cancer among Han Chinese women from South China.

\section{MATERIAL AND METHODS}

\section{Study subjects}

A total of 408 female patients (133 at Nanfang Hospital, 105 at General Hospital of Guangzhou Military Command of the People's Liberation Army, and 170 at Chongqing Cancer Hospital) with pathologically diagnosed breast cancer were included in the study. As normal control subjects, 469 healthy women with no history of cancer were recruited randomly from Nanfang Hospital and Chongqing Cancer Hospital. All subjects were Han Chinese women, and all of the subjects with clinical data provided informed consent before participating in the trial. The mean ages of the patients and controls were 48.03 and 45.94 years, respectively, defined as age at the time of recruitment.

\section{DNA extraction}

Peripheral blood samples were collected from the participants and stored at $-70^{\circ} \mathrm{C}$ until DNA extraction. Genomic DNA was extracted from the samples using an E.Z.N.A. ${ }^{\mathrm{TM}}$ blood DNA kit (Omega Bio-Tek, USA) according to manufacturer instructions. DNA was stored at $-70^{\circ} \mathrm{C}$.

\section{SNP selection and genotyping}

Referring to other studies, we selected 16 SNPs from the Han Chinese data included in the HapMap Project and from the Single Nucleotide Polymorphism database. For each SNP, a pair of amplification primers and an extension primer were designed using Assay Design 3.1 (Sequenom, San Diego, CA, USA). All SNPs were analyzed using a MassARRAY matrixassisted laser desorption/ionization time-of-flight mass spectrometry platform (Sequenom) following manufacturer instructions. The DNA sample quality control threshold was set at $90 \%$ (9/10 successful calls).

\section{Statistical analysis}

We conducted a case-control study adjusted for age, and then performed linkage disequilibrium and haplotype analyses. Association analysis using the odds ratio (OR) and $95 \%$ confidence interval $(95 \% \mathrm{CI})$ was carried out through unconditional logistic regres- 
sion with multiple inheritance models (codominant, dominant, recessive, and overdominant). The statistical analyses were performed using SPSS 13.0 (SPSS, Chicago, IL, USA) and the HaploView 4.2 software (Daly Lab, Cambridge, MA, USA), with the online tool SNPstats (http://bioinfo.iconcologia.net/SNPstats). Hardy-Weinberg equilibrium (HWE) was assessed using the Fisher exact test and the chi-square test. All statistical analyses were two-tailed, and the significance level was set at 0.05 .

\section{RESULTS}

A total of 16 SNPs were genotyped successfully among 877 women from South China. Three SNPs (rs113593938, rs6733301, and rs2424913) with a minor allele frequency of $<0.05$ and 2 (rs11695471 and rs6087990) with a call rate of $<90 \%$ were excluded from subsequent analysis. Two SNPs, rs2228612 and rs11254413, complied with HWE only in Guangdong and Chongqing subjects, respectively. The mean age differed significantly between the breast cancer and control groups $(\mathrm{P}<0.05)$, and thus all statistical tests were adjusted for age.

\section{DNMT polymorphisms and breast cancer for all subjects}

SNPs rs16999593 in DNMT1 and rs2424908 in DNMT3B appeared to be strongly associated with breast cancer susceptibility, as shown in Table 1. The genotype distribution in the breast cancer group for the rs $16999593 \mathrm{SNP}$ was $56.8 \% \mathrm{TT}, 38.6 \% \mathrm{CT}$, and $4.7 \% \mathrm{CC}$, which was significantly different from that in the control group $(67.6 \% \mathrm{TT}, 28.4 \% \mathrm{CT}$, and $4.0 \% \mathrm{CC} ; \mathrm{P}=0.0052$ ). Compared with $\mathrm{TT}$ and $\mathrm{CC}$, the heterozygous genotype $\mathrm{CT}$ appeared to increase breast cancer risk under codominant $(\mathrm{OR}=1.60 ; 95 \% \mathrm{CI}=1.20-2.14)$, dominant $(\mathrm{OR}$ $=1.57 ; 95 \% \mathrm{CI}=1.19-2.07)$, and overdominant models $(\mathrm{OR}=1.57 ; 95 \% \mathrm{CI}=1.18-2.09)$. In contrast, the heterozygous CT genotype of rs 2424908 may be associated with a lower risk for developing breast cancer $(\mathrm{OR}=0.62 ; 95 \% \mathrm{CI}=0.46-0.84 ; \mathrm{P}=0.0061)$. The data for $D N M T 3 L$ and DNMT2 are not shown for all subjects.

\section{DNMT polymorphisms and breast cancer by region}

To investigate whether geographical differences affected the risk association, we conducted a stratification analysis by region. Table 2 shows the stratified analysis of Guangdong and Chongqing subjects. The results for the Guangdong samples were consistent with the overall results for all individuals. In addition, the frequency of the GG genotype of rs2228612 among cases was significantly higher than that among controls $(22.5 v \mathrm{~s} 14.5 \%)$ in the codominant $(\mathrm{OR}=1.71 ; 95 \% \mathrm{CI}=1.06-2.78 ; \mathrm{P}=0.044)$ and recessive $(\mathrm{OR}=1.75 ; 95 \% \mathrm{CI}=$ $1.13-2.72 ; \mathrm{P}=0.013$ ) models. According to the results for the Chongqing samples, rs2424908 was a similarly significant locus, but the genotypic frequencies of rs2228611 and rs2114724 were quite distinct. Genotypes AG of rs2228611 and TC of rs2114724 were associated with an increased risk for breast cancer $(\mathrm{P}=0.044$ for each) in the Chongqing population. The rs11254413 SNP in DNMT2 met HWE only in the Chongqing subjects but was not different between the cases and controls $(\mathrm{P}=0.8)$. All subjects in this study were genotyped as $\mathrm{CC}$ for rs113593938 in DNMT3L (data not shown). 
Table 1. Results of DNMT polymorphisms in the breast cancer case-control group including all subjects.

\begin{tabular}{|c|c|c|c|c|c|c|c|}
\hline Gene & SNPs & Model & Genotype & Control & Case & OR $(95 \% \mathrm{CI})$ & $\mathrm{P}$ \\
\hline \multirow{18}{*}{ DNMTI } & \multirow{3}{*}{ rs2114724 } & \multirow[t]{3}{*}{ Codominant } & $\mathrm{C} / \mathrm{C}$ & $251(53.5 \%)$ & $207(50.9 \%)$ & 1 & \multirow{3}{*}{0.68} \\
\hline & & & $\mathrm{T} / \mathrm{C}$ & $183(39 \%)$ & $166(40.8 \%)$ & $1.10(0.83-1.45)$ & \\
\hline & & & $\mathrm{T} / \mathrm{T}$ & $35(7.5 \%)$ & $34(8.3 \%)$ & $1.21(0.73-2.01)$ & \\
\hline & \multirow[t]{3}{*}{ rs2228611 } & \multirow[t]{3}{*}{ Codominant } & $\mathrm{G} / \mathrm{G}$ & $250(53.3 \%)$ & $207(50.9 \%)$ & 1 & \multirow[t]{3}{*}{0.71} \\
\hline & & & $\mathrm{A} / \mathrm{G}$ & $184(39.2 \%)$ & $166(40.8 \%)$ & $1.09(0.82-1.44)$ & \\
\hline & & & $\mathrm{A} / \mathrm{A}$ & $35(7.5 \%)$ & $34(8.3 \%)$ & $1.20(0.72-2.00)$ & \\
\hline & \multirow[t]{3}{*}{ rs8101866 } & \multirow[t]{3}{*}{ Codominant } & $\mathrm{T} / \mathrm{T}$ & $250(53.3 \%)$ & $207(51 \%)$ & 1 & \multirow[t]{3}{*}{0.72} \\
\hline & & & $\mathrm{C} / \mathrm{T}$ & $183(39 \%)$ & $164(40.4 \%)$ & $1.08(0.82-1.43)$ & \\
\hline & & & $\mathrm{C} / \mathrm{C}$ & $36(7.7 \%)$ & $35(8.6 \%)$ & $1.21(0.73-1.99)$ & \\
\hline & \multirow[t]{9}{*}{ rs16999593 } & \multirow[t]{3}{*}{ Codominant } & $\mathrm{T} / \mathrm{T}$ & $317(67.6 \%)$ & $231(56.8 \%)$ & 1 & \multirow[t]{3}{*}{0.0052} \\
\hline & & & $\mathrm{C} / \mathrm{T}$ & $133(28.4 \%)$ & $157(38.6 \%)$ & $1.60(1.20-2.14)$ & \\
\hline & & & $\mathrm{C} / \mathrm{C}$ & $19(4 \%)$ & $19(4.7 \%)$ & $1.35(0.70-2.62)$ & \\
\hline & & \multirow[t]{2}{*}{ Dominant } & $\mathrm{T} / \mathrm{T}$ & $317(67.6 \%)$ & $231(56.8 \%)$ & 1 & \multirow[t]{2}{*}{0.0013} \\
\hline & & & $\mathrm{C} / \mathrm{T}-\mathrm{C} / \mathrm{C}$ & $152(32.4 \%)$ & $176(43.2 \%)$ & $1.57(1.19-2.07)$ & \\
\hline & & \multirow[t]{2}{*}{ Recessive } & $\mathrm{T} / \mathrm{T}-\mathrm{C} / \mathrm{T}$ & $450(96 \%)$ & $388(95.3 \%)$ & 1 & \multirow[t]{2}{*}{0.68} \\
\hline & & & $\mathrm{C} / \mathrm{C}$ & $19(4 \%)$ & $19(4.7 \%)$ & $1.15(0.60-2.21)$ & \\
\hline & & \multirow[t]{2}{*}{ Overdominant } & $\mathrm{T} / \mathrm{T}-\mathrm{C} / \mathrm{C}$ & $336(71.6 \%)$ & $250(61.4 \%)$ & 1 & \multirow[t]{2}{*}{0.0018} \\
\hline & & & $\mathrm{C} / \mathrm{T}$ & $133(28.4 \%)$ & $157(38.6 \%)$ & $1.57(1.18-2.09)$ & \\
\hline \multirow[t]{12}{*}{ DNMT3A } & \multirow[t]{3}{*}{ rs 13420827} & \multirow[t]{3}{*}{ Codominant } & $\mathrm{C} / \mathrm{C}$ & $291(62 \%)$ & $258(63.4 \%)$ & 1 & \multirow[t]{3}{*}{0.85} \\
\hline & & & $\mathrm{G} / \mathrm{C}$ & $158(33.7 \%)$ & $131(32.2 \%)$ & $0.93(0.70-1.25)$ & \\
\hline & & & $\mathrm{G} / \mathrm{G}$ & $20(4.3 \%)$ & $18(4.4 \%)$ & $1.10(0.57-2.13)$ & \\
\hline & \multirow[t]{3}{*}{ rs 11887120} & \multirow[t]{3}{*}{ Codominant } & $T / T$ & $136(29 \%)$ & $114(28 \%)$ & 1 & 0.91 \\
\hline & & & $\mathrm{C} / \mathrm{T}$ & $216(46.1 \%)$ & $194(47.7 \%)$ & $1.07(0.78-1.47)$ & \\
\hline & & & $\mathrm{C} / \mathrm{C}$ & $117(24.9 \%)$ & $99(24.3 \%)$ & $1.01(0.70-1.46)$ & \\
\hline & rs13428812 & Codominant & $\mathrm{A} / \mathrm{A}$ & $249(53.1 \%)$ & $210(51.6 \%)$ & 1 & 0.28 \\
\hline & & & $\mathrm{G} / \mathrm{A}$ & $185(39.5 \%)$ & $176(43.2 \%)$ & $1.13(0.85-1.49)$ & \\
\hline & & & $\mathrm{G} / \mathrm{G}$ & $35(7.5 \%)$ & $21(5.2 \%)$ & $0.72(0.40-1.28)$ & \\
\hline & rs 1550117 & Codominant & $\mathrm{G} / \mathrm{G}$ & $282(60.3 \%)$ & $250(61.4 \%)$ & 1 & 0.2 \\
\hline & & & $\mathrm{A} / \mathrm{G}$ & $166(35.5 \%)$ & $130(31.9 \%)$ & $0.87(0.65-1.16)$ & \\
\hline & & & $\mathrm{A} / \mathrm{A}$ & $20(4.3 \%)$ & $27(6.6 \%)$ & $1.50(0.82-2.75)$ & \\
\hline DNMT3B & rs 2424908 & Codominant & $\mathrm{T} / \mathrm{T}$ & $144(30.7 \%)$ & $160(39.3 \%)$ & 1 & 0.0061 \\
\hline & & & $\mathrm{C} / \mathrm{T}$ & $242(51.6 \%)$ & $167(41 \%)$ & $0.62(0.46-0.84)$ & \\
\hline & & & $\mathrm{C} / \mathrm{C}$ & $83(17.7 \%)$ & $80(19.7 \%)$ & $0.85(0.58-1.25)$ & \\
\hline & & Dominant & $\mathrm{T} / \mathrm{T}$ & $144(30.7 \%)$ & $160(39.3 \%)$ & & 0.0069 \\
\hline & & & $\mathrm{C} / \mathrm{T}-\mathrm{C} / \mathrm{C}$ & $325(69.3 \%)$ & $247(60.7 \%)$ & $0.68(0.51-0.90)$ & \\
\hline & & Recessive & $\mathrm{T} / \mathrm{T}-\mathrm{C} / \mathrm{T}$ & $386(82.3 \%)$ & $327(80.3 \%)$ & & 0.51 \\
\hline & & & $\mathrm{C} / \mathrm{C}$ & $83(17.7 \%)$ & $80(19.7 \%)$ & $1.12(0.80-1.58)$ & \\
\hline & & Overdominant & $\mathrm{T} / \mathrm{T}-\mathrm{C} / \mathrm{C}$ & $227(48.4 \%)$ & $240(59 \%)$ & & 0.002 \\
\hline & & & $\mathrm{C} / \mathrm{T}$ & $242(51.6 \%)$ & $167(41 \%)$ & $0.66(0.50-0.86)$ & \\
\hline
\end{tabular}

$\mathrm{OR}=$ odds ratio and $95 \% \mathrm{CI}=95 \%$ confidence interval are counted by the web-based tool SNPstats and adjusted by age. $\mathrm{P}$ is counted by the web-based tool SNPstats. Values in bold are positive results.

\section{Linkage disequilibrium (LD) and haplotype analyses}

To evaluate the correlations of SNPs in the same gene, we performed LD and haplotype analyses. The LD statistics of the DNMT1 and DNMT3A polymorphisms are presented in Table 3, and the corresponding structures are shown in Figure 1. The rs2114724, rs2228611, and rs8101866 SNPs in DNMT1 exhibited strong LD ( $\left.\mathrm{D}^{\prime} \geq 0.994, \mathrm{r}^{2} \geq 0.983, \mathrm{P}<0.001\right)$ and formed a haplotype block (Figure 1A). The SNPs in DNMT3A had weak LD (Figure 1B). Table 4 shows the haplotype associations in the case and control groups. For DNMT1, the distribution of CGTC haplotype of rs2114724, rs2228611, rs8101866, and rs16999593 differed significantly between the two groups, with a frequency of 0.2085 compared with the highest of 0.5107 for CGTT haplotype $(\mathrm{OR}=1.51 ; 95 \% \mathrm{CI}=1.18-1.93 ; \mathrm{P}=0.0012)$. A marginal difference in the frequency of the CCGA haplotype of DNMT3A was also found. 
Polymorphisms of DNMT1 and DNMT3B and breast cancer risk

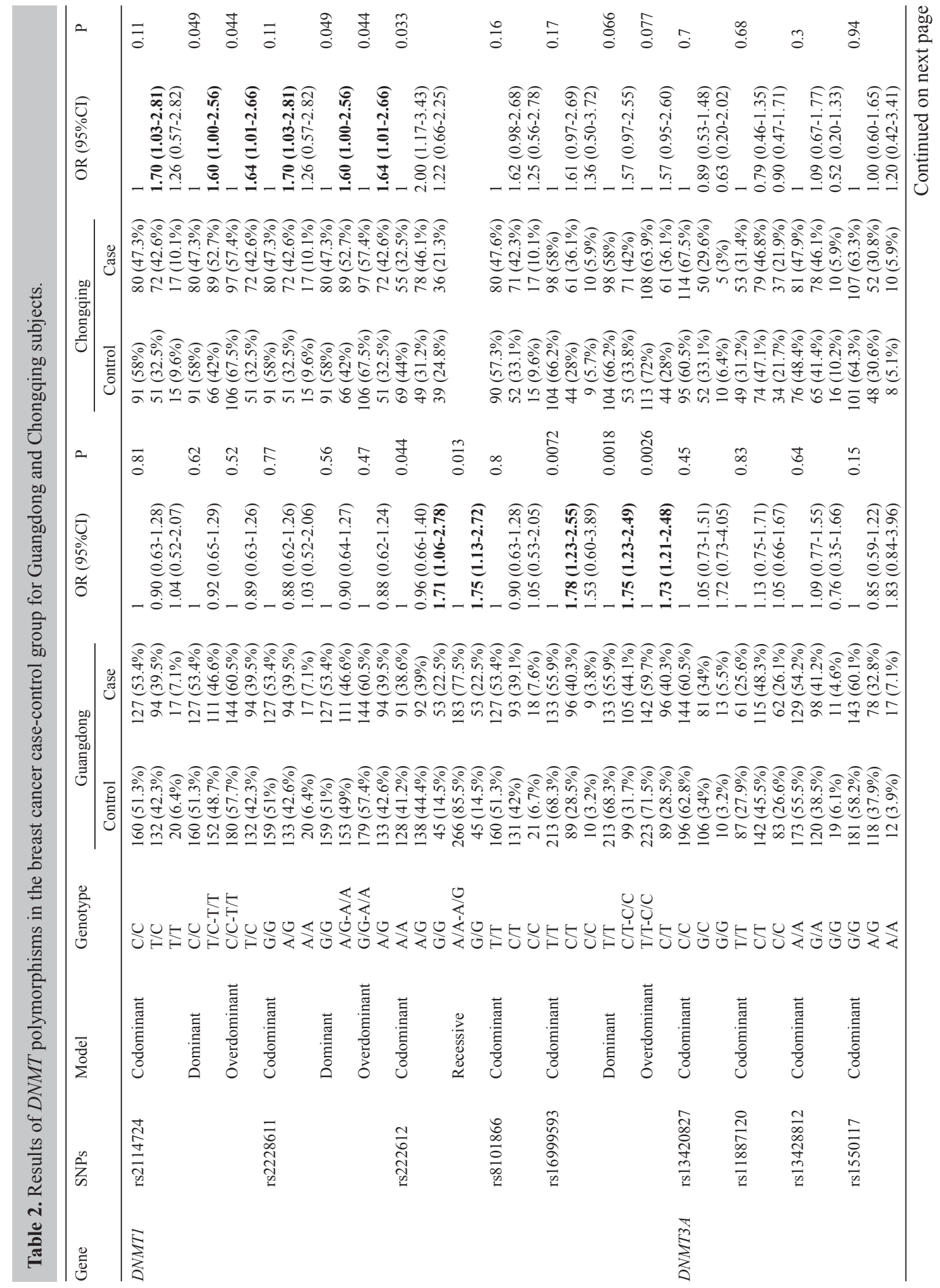

Genetics and Molecular Research 11 (4): 4330-4341 (2012) 


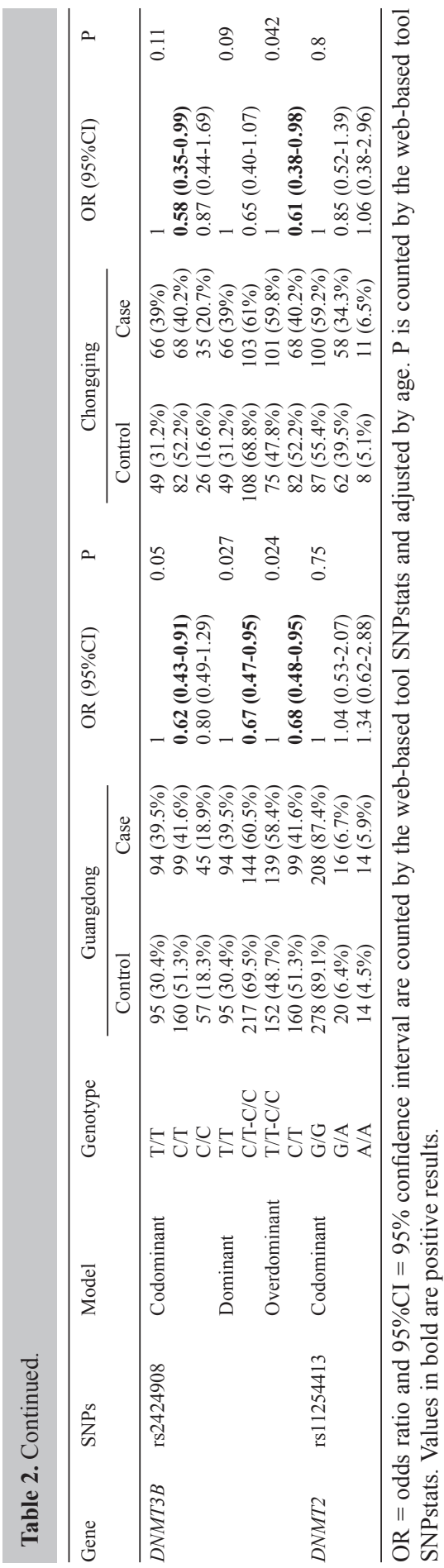


Table 3. Linkage disequilibrium analysis results of $D N M T 1$ and $D N M T 3 A$ polymorphisms including all subjects.

\begin{tabular}{|c|c|c|c|c|c|c|}
\hline Gene & Rs 1 & Rs 2 & $\mathrm{D}^{\prime}$ & $r^{2}$ & $\chi^{2}$ & $\mathrm{P}$ \\
\hline \multirow[t]{6}{*}{$D N M T 1$} & rs2114724 & rs2228611 & 1 & 0.997 & 1746 & $<0.001$ \\
\hline & rs2114724 & rs8101866 & 0.997 & 0.986 & 1726 & $<0.001$ \\
\hline & rs2114724 & rs16999593 & 1 & 0.102 & 178 & $<0.001$ \\
\hline & rs2228611 & rs8101866 & 0.994 & 0.983 & 1721 & $<0.001$ \\
\hline & rs2228611 & rs16999593 & 1 & 0.102 & 178 & $<0.001$ \\
\hline & rs8101866 & rs16999593 & 1 & 0.103 & 179 & $<0.001$ \\
\hline \multirow[t]{6}{*}{ DNMT3A } & rs13420827 & rs 11887120 & 0.663 & 0.107 & 187.33 & $<0.001$ \\
\hline & rs 13420827 & rs13428812 & 0.517 & 0.026 & 45.53 & $<0.001$ \\
\hline & rs 13420827 & rs 1550117 & 0.216 & 0.043 & 76.06 & $<0.001$ \\
\hline & rs11887120 & rs13428812 & 0.093 & 0.003 & 6.09 & 0.0136 \\
\hline & rs11887120 & rs1550117 & 0.057 & 0.001 & 1.05 & 0.2206 \\
\hline & rs 13428812 & rs1550117 & 0.64 & 0.044 & 74.9 & $<0.001$ \\
\hline
\end{tabular}

$\mathrm{D}^{\prime}$ and $\mathrm{r}^{2}$ are counted by the HaploView 4.2 software. $\chi^{2}$ and P are counted by the web-based tool SNPstats.

A

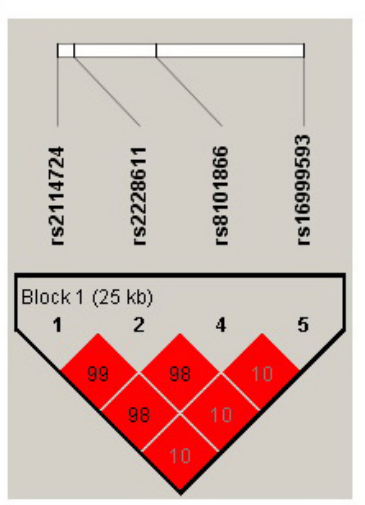

B

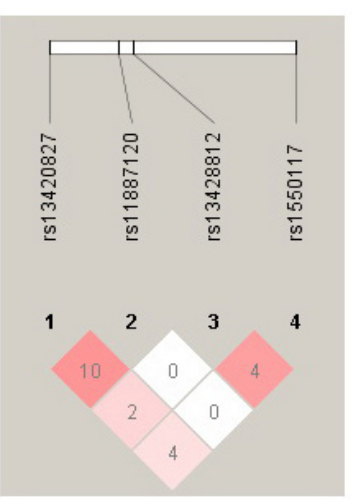

Figure 1. Linkage disequilibrium structure of DNMT1 (A) and DNMT3A (B) SNPs. Values are shown in $\mathrm{r}^{2}$.

\begin{tabular}{|c|c|c|c|c|c|c|c|}
\hline DNMT1 & rs2114724 & rs2228611 & rs8101866 & rs16999593 & Frequency & OR $(95 \% \mathrm{CI})$ & $\mathrm{P}$ \\
\hline 1 & $\mathrm{C}$ & G & $\mathrm{T}$ & $\mathrm{T}$ & 0.5107 & 1 & - \\
\hline 2 & $\mathrm{~T}$ & A & $\mathrm{C}$ & $\mathrm{T}$ & 0.2774 & $1.23(0.99-1.53)$ & 0.068 \\
\hline 3 & $\mathrm{C}$ & G & $\mathrm{T}$ & $\mathrm{C}$ & 0.2085 & 1.51 (1.18-1.93) & 0.0012 \\
\hline Rare & * & * & * & * & 0.0034 & $0.26(0.01-4.93)$ & 0.37 \\
\hline DNMT3A & rs13420827 & rs11887120 & rs13428812 & rs1550117 & Frequency & OR $(95 \% \mathrm{CI})$ & $\mathrm{P}$ \\
\hline 1 & $\mathrm{C}$ & $\mathrm{C}$ & A & G & 0.2381 & 1 & - \\
\hline 2 & $\mathrm{C}$ & $\mathrm{T}$ & A & G & 0.189 & $1.00(0.69-1.46)$ & 0.99 \\
\hline 3 & $\mathrm{C}$ & $\mathrm{C}$ & G & G & 0.1214 & $0.88(0.57-1.36)$ & 0.56 \\
\hline 4 & $\mathrm{C}$ & $\mathrm{T}$ & G & G & 0.101 & $0.87(0.58-1.32)$ & 0.51 \\
\hline 5 & G & $\mathrm{T}$ & A & G & 0.0812 & $1.11(0.70-1.75)$ & 0.66 \\
\hline 6 & G & $\mathrm{T}$ & A & A & 0.0696 & $0.74(0.45-1.23)$ & 0.25 \\
\hline 7 & $\mathrm{C}$ & $\mathrm{C}$ & A & A & 0.0672 & $0.81(0.45-1.47)$ & 0.49 \\
\hline 8 & $\mathrm{C}$ & $\mathrm{T}$ & A & A & 0.054 & $1.02(0.59-1.77)$ & 0.93 \\
\hline 9 & G & $\mathrm{T}$ & G & G & 0.0247 & $1.05(0.42-2.62)$ & 0.92 \\
\hline 10 & $\mathrm{C}$ & $\mathrm{C}$ & G & A & 0.021 & $2.73(1.03-7.24)$ & 0.044 \\
\hline 11 & G & $\mathrm{C}$ & A & G & 0.0199 & $0.75(0.28-1.98)$ & 0.56 \\
\hline 12 & G & $\mathrm{C}$ & A & A & 0.0111 & $1.61(0.39-6.66)$ & 0.51 \\
\hline
\end{tabular}

$\mathrm{OR}=$ odds ratio and $95 \% \mathrm{CI}=95 \%$ confidence interval are counted by the web-based tool SNPstats and adjusted by age. $\mathrm{P}$ is counted by the web-based tool SNPstats. Values in bold are positive results. 


\section{DISCUSSION}

By modulating gene expression capacity, epigenetic alterations play an important role in tumor progression (Jones and Baylin, 2002). Aberrant promoter hypermethylation is well known to inactivate many tumor suppressor genes, including the breast cancer 1 and 2 genes (Esteller et al., 2000; Potapova et al., 2008; Moelans et al., 2011). Research efforts have focused on hypermethylation by the 3 active DNMTs: DNMT1, DNMT3A, and DNMT3B. Common variants of these genes are associated with susceptibility to several cancers, including breast cancer (Kanai et al., 2003; Montgomery et al., 2004; Cebrian et al., 2006; Kelemen et al., 2008; Liu et al., 2008; Xiang et al., 2010; Fan et al., 2010; Hu et al., 2010), as altered enzyme activities can disrupt the methylation balance in cells. At present, only 2 studies have assessed the associations between DNMT polymorphisms and breast cancer in Chinese populations, and the results are controversial (Ye et al., 2010; Xiang et al., 2010). Therefore, we conducted this study to determine the relationships between DNMT variants and breast cancer risk in a Chinese population from South China.

Many studies have reported associations between $D N M T$ polymorphisms, especially those of DNMT1, DNMT3A, and DNMT3B, and diseases such as cancer. DNMT1, which catalyzes the post-replicative synthesis of 5-methylcytosine in DNA, is crucial for the maintenance of methylation, gene regulation, and chromatin stability. DNMT1 is associated with heterochromatin throughout the G2 and M phases of the cell cycle and is loaded onto the replication fork during S phase (Easwaran et al., 2004). Variants of DNMT1 can cause aberrant methylation, resulting in complex pathological processes. Polymorphisms in DNMT1 have been reported to be associated with risks for human breast cancer (Xiang et al., 2010), colorectal cancer (Kanai et al., 2003), and ovarian cancer (Kelemen et al., 2008) and with mutagen sensitivity (Leng et al., 2008) and intelligence (Haggarty et al., 2010).

In the present study, genotype CT of rs 16999593 in DNMT1 was strongly correlated with an increased risk for breast cancer in the Chinese study population. However, in a study of the Heilongjiang population, the frequency of the CT genotype was lower in patients than in controls (Xiang et al., 2010). We also found evidence for an association of breast cancer susceptibility with rs2228612 in Guangdong subjects and with rs2114724 together with rs2228611 in Chongqing subjects. Furthermore, 3 SNPs in DNMT1 (rs2114724, rs2228611, and rs8101866), which showed various frequencies between cases and controls, were in strong LD with each other and formed a haplotype block. These results suggest that polymorphisms in DNMT1 may be related to breast cancer susceptibility among South China Han Chinese women.

DNMT3A and DNMT3B are essential for de novo methylation during early mammalian development. DNMT3A can interact with zinc finger protein 238, histone deacetylase 1, and Myc to repress transcription (Fuks et al., 2001; Brenner et al., 2005). Polymorphisms of DNMT3A have been reported to be associated with several biological processes, including skeletal and intelligence development (Gudbjartsson et al., 2008; Haggarty et al., 2010), and ovarian cancer (Kelemen et al., 2008), gastric cancer (Fan et al., 2010), and Crohn's disease susceptibility (Franke et al., 2010). Recent studies have found that DNMT3A mutations are frequent in myelodysplastic syndrome (Walter et al., 2011) and acute myeloid leukemia and have an unfavorable prognosis (Ley et al., 2010; Thol et al., 2011). Our data showed no significant association between DNMT3A polymorphisms and 
breast cancer risk in our Chinese population. DNMT3B interacts with many proteins such as heterochromatin protein 1 homolog alpha, small ubiquitin-related modifier 1, ubiquitinconjugating enzyme E2I, DNMT1, and DNMT3A during DNA methylation (Kang et al., 2001; Kim et al., 2002; Lehnertz et al., 2003). Unlike DNMT3A, DNMT3B requires a DNA cofactor to bind stably to S-adenosyl-1-methionine and carry out its catalytic function. Montgomery et al. (2004) have demonstrated that rs 2424913 in DNMT3B is significantly associated with breast cancer risk in a British population; compared with the TT genotype, the $\mathrm{CC}$ and $\mathrm{CT}$ genotypes appear to increase breast cancer risk significantly (OR $=1.51 ; 95 \% \mathrm{CI}=1.01-2.25)$. Shen et al. (2002) and Liu et al. (2008) have reported that $D N M T 3 B$ genotypes with the $\mathrm{T}$ allele are associated with increased risk for squamous cell carcinoma of the head and neck and lung cancer in Western populations. Another DNMT3B SNP, rs6087990, significantly affects promoter activity and is associated with a $50 \%$ reduction in lung cancer risk in a Korean population (Lee et al., 2005). However, these 2 DNMT3B SNPs were excluded from the present analysis owing to a lack of polymorphisms or poor genotyping results in our population. The current study revealed that genotype CT of rs 2424908 in $D N M 3 B$ was associated with a reduced risk for breast cancer in the overall study population as well as in the Guangdong and Chongqing women. These results differ from those of another study, which reported no association of DNMT1 and DNMT3B polymorphisms with breast cancer risk in Chinese women (Ye et al., 2010). These apparently disparate results suggest that the diversity of gene polymorphisms varies according to geographic region and environmental conditions.

DNMT3L is closely related to DNMT3A and DNMT3B structurally, but it has no catalytic activity because it lacks the amino acid residues necessary for methyltransferase activity. Nevertheless, DNMT3L cooperates with DNMT3A and DNMT3B to modulate de novo methylation (Wienholz et al., 2010). DNMT3L can also mediate transcriptional repression through interactions with histone deacetylase 1 (Deplus et al., 2002). DNMT2, also known as tRNA aspartic acid methyltransferase 1, is similar to other DNA cytosine methyltransferases in sequence and structure, but instead of methylating DNA, it methylates cytosine 38 in the anticodon loop of aspartic acid tRNA (Goll et al., 2006). No previous study has investigated the association between $D N M T 3 L$ or $D N M T 2$ polymorphisms and breast cancer. Our data showed that rs 11254413 in DNMT2 met HWE only in Chongqing subjects and displayed no difference between cases and controls. All subjects in this study were genotyped as CC for rs 113593938 in $D N M T 3 L$. No further statistical analysis was carried out for these genes.

Variations in DNA methyltransferases may cause aberrant expression of tumor-related genes by affecting the DNA methylation status in breast cancer, as in other cancers. As epigenetic alterations are reversible, DNA methyltransferases represent potential targets for epigenetic therapy using DNMT inhibitors (Egger et al., 2004; Cai et al., 2011). This study is the first to evaluate associations between the polymorphisms of $5 D N M T$ s and breast cancer in populations of South China. The results indicate that variants of DNMT1 and DNMT3B have some relevance to breast cancer risk. The DNMT1 rs16999593 polymorphism was strongly correlated with an increased risk for breast cancer, and rs 2424908 in DNM3B was associated with a reduced risk, although regional differences and molecular mechanisms were not fully elucidated. Further studies are necessary to verify these associations in larger populations and to identify the functional significance of DNA methylation to assess associations between $D N M T$ polymorphisms and breast cancer risk comprehensively. 


\section{ACKNOWLEDGMENTS}

Research supported by the Key Programs for Science and Technology Development of Guangzhou (\#2008A1-E4151) and the National High Technology Research and Development Program of China (\#2006AA02A311).

\section{REFERENCES}

Bestor TH (2000). The DNA methyltransferases of mammals. Hum. Mol. Genet. 9: 2395-2402.

Brenner C, Deplus R, Didelot C, Loriot A, et al. (2005). Myc represses transcription through recruitment of DNA methyltransferase corepressor. EMBO J. 24: 336-346.

Cai FF, Kohler C, Zhang B, Wang MH, et al. (2011). Epigenetic therapy for breast cancer. Int. J. Mol. Sci. 12: 4465-4487.

Cebrian A, Pharoah PD, Ahmed S, Ropero S, et al. (2006). Genetic variants in epigenetic genes and breast cancer risk. Carcinogenesis 27: 1661-1669.

Deplus R, Brenner C, Burgers WA, Putmans P, et al. (2002). Dnmt3L is a transcriptional repressor that recruits histone deacetylase. Nucleic Acids Res. 30: 3831-3838.

Easwaran HP, Schermelleh L, Leonhardt H and Cardoso MC (2004). Replication-independent chromatin loading of Dnmt1 during G2 and M phases. EMBO Rep. 5: 1181-1186.

Egger G, Liang G, Aparicio A and Jones PA (2004). Epigenetics in human disease and prospects for epigenetic therapy. Nature 429: 457-463.

Ehrlich M (2002). DNA methylation in cancer: too much, but also too little. Oncogene 21: 5400-5413.

Esteller M, Silva JM, Dominguez G, Bonilla F, et al. (2000). Promoter hypermethylation and BRCA1 inactivation in sporadic breast and ovarian tumors. J. Natl. Cancer Inst. 92: 564-569.

Fan H, Liu D, Qiu X, Qiao F, et al. (2010). A functional polymorphism in the DNA methyltransferase-3A promoter modifies the susceptibility in gastric cancer but not in esophageal carcinoma. BMC Med. 8: 12.

Franke A, McGovern DP, Barrett JC, Wang K, et al. (2010). Genome-wide meta-analysis increases to 71 the number of confirmed Crohn's disease susceptibility loci. Nat. Genet. 42: 1118-1125.

Fuks F, Burgers WA, Godin N, Kasai M, et al. (2001). Dnmt3a binds deacetylases and is recruited by a sequence-specific repressor to silence transcription. EMBO J. 20: 2536-2544.

Goll MG, Kirpekar F, Maggert KA, Yoder JA, et al. (2006). Methylation of tRNAAsp by the DNA methyltransferase homolog Dnmt2. Science 311: 395-398.

Gudbjartsson DF, Walters GB, Thorleifsson G, Stefansson H, et al. (2008). Many sequence variants affecting diversity of adult human height. Nat. Genet. 40: 609-615.

Haggarty P, Hoad G, Harris SE, Starr JM, et al. (2010). Human intelligence and polymorphisms in the DNA methyltransferase genes involved in epigenetic marking. PLoS One 5: e11329.

Herman JG and Baylin SB (2003). Gene silencing in cancer in association with promoter hypermethylation. N. Engl. J. Med. 349: 2042-2054.

Hu J, Fan H, Liu D, Zhang S, et al. (2010). DNMT3B promoter polymorphism and risk of gastric cancer. Dig. Dis. Sci. 55: 1011-1016.

Jemal A, Bray F, Center MM, Ferlay J, et al. (2011). Global cancer statistics. CA Cancer J. Clin. 61: 69-90.

Jones PA and Baylin SB (2002). The fundamental role of epigenetic events in cancer. Nat. Rev. Genet. 3: 415-428.

Kanai Y, Ushijima S, Nakanishi Y, Sakamoto M, et al. (2003). Mutation of the DNA methyltransferase (DNMT) 1 gene in human colorectal cancers. Cancer Lett. 192: 75-82.

Kang ES, Park CW and Chung JH (2001). Dnmt3b, de novo DNA methyltransferase, interacts with SUMO-1 and Ubc9 through its N-terminal region and is subject to modification by SUMO-1. Biochem. Biophys. Res. Commun. 289: 862-868.

Kelemen LE, Sellers TA, Schildkraut JM, Cunningham JM, et al. (2008). Genetic variation in the one-carbon transfer pathway and ovarian cancer risk. Cancer Res. 68: 2498-2506.

Kim GD, Ni J, Kelesoglu N, Roberts RJ, et al. (2002). Co-operation and communication between the human maintenance and de novo DNA (cytosine-5) methyltransferases. EMBO J. 21: 4183-4195.

Lee SJ, Jeon HS, Jang JS, Park SH, et al. (2005). DNMT3B polymorphisms and risk of primary lung cancer. Carcinogenesis 26: 403-409.

Lehnertz B, Ueda Y, Derijck AA, Braunschweig U, et al. (2003). Suv39h-mediated histone H3 lysine 9 methylation directs DNA methylation to major satellite repeats at pericentric heterochromatin. Curr. Biol. 13: 1192-1200. 
Leng S, Stidley CA, Bernauer AM, Picchi MA, et al. (2008). Haplotypes of DNMT1 and DNMT3B are associated with mutagen sensitivity induced by benzo[a]pyrene diol epoxide among smokers. Carcinogenesis 29: 1380-1385.

Ley TJ, Ding L, Walter MJ, McLellan MD, et al. (2010). DNMT3A mutations in acute myeloid leukemia. N. Engl. J. Med. 363: 2424-2433.

Liu Z, Wang L, Wang LE, Sturgis EM, et al. (2008). Polymorphisms of the DNMT3B gene and risk of squamous cell carcinoma of the head and neck: a case-control study. Cancer Lett. 268: 158-165.

McCabe DC and Caudill MA (2005). DNA methylation, genomic silencing, and links to nutrition and cancer. Nutr. Rev. 63: 183-195.

Moelans CB, Verschuur-Maes AH and van Diest PJ (2011). Frequent promoter hypermethylation of BRCA2, CDH13, MSH6, PAX5, PAX6 and WT1 in ductal carcinoma in situ and invasive breast cancer. J. Pathol. 225: 222-231.

Montgomery KG, Liu MC, Eccles DM and Campbell IG (2004). The DNMT3B C $\rightarrow$ T promoter polymorphism and risk of breast cancer in a British population: a case-control study. Breast Cancer Res. 6: R390-R394.

Potapova A, Hoffman AM, Godwin AK, Al-Saleem T, et al. (2008). Promoter hypermethylation of the PALB2 susceptibility gene in inherited and sporadic breast and ovarian cancer. Cancer Res. 68: 998-1002.

Shen H, Wang L, Spitz MR, Hong WK, et al. (2002). A novel polymorphism in human cytosine DNA-methyltransferase3B promoter is associated with an increased risk of lung cancer. Cancer Res. 62: 4992-4995.

Thol F, Damm F, Ludeking A, Winschel C, et al. (2011). Incidence and prognostic influence of DNMT3A mutations in acute myeloid leukemia. J. Clin. Oncol. 29: 2889-2896.

Walter MJ, Ding L, Shen D, Shao J, et al. (2011). Recurrent DNMT3A mutations in patients with myelodysplastic syndromes. Leukemia 25: 1153-1158.

Wienholz BL, Kareta MS, Moarefi AH, Gordon CA, et al. (2010). DNMT3L modulates significant and distinct flanking sequence preference for DNA methylation by DNMT3A and DNMT3B in vivo. PLoS Genet. 6.

Xiang G, Zhenkun F, Shuang C, Jie Z, et al. (2010). Association of DNMT1 gene polymorphisms in exons with sporadic infiltrating ductal breast carcinoma among Chinese Han women in the Heilongjiang Province. Clin. Breast Cancer 10: 373-377.

Ye C, Beeghly-Fadiel A, Lu W, Long J, et al. (2010). Two-stage case-control study of DNMT-1 and DNMT-3B gene variants and breast cancer risk. Breast Cancer Res. Treat. 121: 765-769. 